\title{
Prenatal Invasive Fetal Karyotyping in the Era of First Trimester Screening and Noninvasive Prenatal Testing (NIPT)
}

Christel Eckmann-Scholz, C. Berninghaus, A. Farrokh, N.Maass and I. Alkatotut

Department of Gynecology \& Obstetrics, University Hospital Schleswig-Holstein, Campus Kiel \& Christian-Albrechts-University Kiel, Kiel, Germany

\begin{abstract}
Objective: To validate indications for invasive fetal karyotyping in the era of first trimester screening and non invasive prenatal testing.

Materials and Methods: We conducted single centre retrospective study between 2009 and 2014 . Patients were referred for either first trimester screening or second/ third trimester ultrasound screening. We included all women with invasive testing such as chorionicvilli sampling (CVS) or amniocentesis (AC). The indications for invasive testings were related to suspicious first trimester screening results and pathologic ultrasound findings. Fetal karyotypes and pregnancy outcomes were documented.

Results: A total of 724 patients had an AC (69\%) or CVS (31\%), either. We detected 123 pathologic karyotypes (17\%), i.e. 46 trisomy 21 cases, 24 trisomy 18 cases and four trisomy 13 cases. 601 fetuses had normal karyotypes ( $83 \%) .63$ pathologic karyotypes were diagnosed by AC (52\%)and 60 by CVS(48\%). The main indication for CVS was a suspicious first trimester screening (44\%), whereas AC indications were maternal age, suspicious ultrasound findings or genetic indications (e.g. family history).

From 189(27\%) normal fetal karyotypes, $115(60 \%)$ had an invasive testing due to suspicious biochemistry results. 36 fetuses (19\%) had nuchal translucency (NT) measurements above $2.5 \mathrm{~mm}$ and 38 patients (21\%) had a combined risk elevation. 60 of these cases had cut-off risks for invasive procedures by combined testing of less than 1:50.

Conclusion: Fetal karyotyping is reasonable in high risk situations such as suspicious ultrasound findings in any time of pregnancies. Suspicious biochemistry results from first trimester screening alone may be followed by non-invasive testings (NIPT), especially in high risk pregnancies after ART.
\end{abstract}

\section{Publication History:}

Received: January 15, 2016

Accepted: May 15, 2016

Published: May 17, 2016

\section{Keywords:}

Noninvasive prenatal testing, Prenatal invasive fetal karyotyping,

\section{Introduction}

The screening for fetal aneuploidies in pregnancies started about 60 years ago. Until the beginning of the 1990s advanced maternal age was the main indication for invasive fetal karyotyping. The description of an elevated nuchal translucency in combination with maternal serum markers by Nicolaides and co-workers made it possible to offer a non-invasive screening test to all pregnant women assessing their individual risk of having a fetus with an aneuploidy [1]. Nowadays, the decision for aninvasive prenatal diagnostic testing is frequently based on these results. First trimester screening including ultrasonographic measurement of the nuchal translucency (NT) with combined analysis of pregnancy-associated plasma protein (PAPP-A) and free $B$-chorionic gonadotropine (free $\mathrm{B}$-HCG) has become a widely used screening method to identify chromosomal aberrations in fetuses[1] Furthermore, an increased NT can be associated with other abnormal findings such as heart defects and numerous genetic syndromes[2], but it may as well go along with a normal fetal outcome[3].

On surplus, the screening for the most frequent aberrant numeric karyotypes such as trisomy 21, 13 and 18 comprises ultrasound with respect to fetal malformations such as cardiac defects, abdominal wall defects, growth restriction or absent nasal bone, for example [4].

Since the beginnings of invasive prenatal testing by amniocentesis or chorionic villi sampling, the majorproblem was the number of procedure related fetal losses. Many studies proof that the risk of an abortion after CVS or AC is dependent on the operator. It may range from as low as $0.19 \%$ up to $1.53 \%$ based on results from various studies [5]. Many of these studies were conducted decades ago and probably may not provide an accurate estimate of the current procedure-related risks. Very recently, Akolekar and co-workers performed a systematic review and metaanalysis on this issue and found the procedure related risks of miscarriage much lower than previously reported [6]. Nonetheless the number of invasive procedures has declined over the last two decades due to the very good results from first trimester screening in the hands of experts and due to the implementation of non-invasive prenatal testing for, at least, trisomy 21, 18 and 13.

In our retrospective single centre study we tried to evaluate the different indications for invasive fetal karyotyping. We also checked the reliability of indications for invasive testing with respect to the results from first trimester screening.

\section{Methods and Material}

This is a retrospective analysis of all pregnancies referred to our single major tertiary care centre of prenatal diagnostics for first trimester screening between 2009 and 2014. Screening was performed according to the guidelines of the Fetal Medicine Foundation (FMF) London [7]. All patient data were documented in the electronic database of our hospital, PIA Fetal Database (TM) (GE, USA).

All ultrasound examinations were performed by the same experienced sonographer in prenatal diagnostics using a transabdominal probe (4-8 MHz Voluson E8; GE Medical Systems) according to the guidelines of the Fetal Medicine Foundation (FMF)

"Corresponding Author: Dr. Christel Eckmann-Scholz, Department of Gynecology \& Obstetrics, University Hospital Schleswig-Holstein, Campus Kiel, Arnold-Heller-Straße 3, Germany; E-mail: christel.eckmann@uksh.de

Citation: Eckmann-Scholz C, Berninghaus C, Farrokh A, Maass N, Alkatotut I (2016) Prenatal Invasive Fetal Karyotyping in the Era of First Trimester Screening and Noninvasive Prenatal Testing (NIPT). Int J Gynecol Clin Pract 3: 116. doi: http://dx.doi.org/10.15344/2394-4986/2016/116

Copyright: (c) 2016 Eckmann-Scholz et al. This is an open-access article distributed under the terms of the Creative Commons Attribution License, which permits unrestricted use, distribution, and reproduction in any medium, provided the original author and source are credited. 
Citation: Eckmann-Scholz C, Berninghaus C, Farrokh A, Maass N, Alkatotut I (2016) Prenatal Invasive Fetal Karyotyping in the Era of First Trimester Screening and Noninvasive Prenatal Testing (NIPT). Int J Gynecol Clin Pract 3: 116. doi: http://dx.doi.org/10.15344/2394-4986/2016/116

Page 2 of 4

London[7]. Data were documented in the PIA Fetal Database.

The inclusion criteria: All patients who had an invasive fetal karyotyping over a period of six years from January 1, 2009 to December 31, 2014 were included. As there were no failures in fetal karyotyping in any case, we did not have to define any exclusion criteria.

After informed consent of the patients invasive prenatal diagnosis was performed by either chorionic villi sampling (CVS) or amniocentesis (AC) by one single expert in prenatal diagnostics. All invasive procedures were ultrasound guided and performed by freehanded needle insertion.

Whenever malformations or chromosomal aberrations were diagnosed, human genetic counselling was offered to the patients.

Approval by the local Ethical Committee was given.

\section{Results}

Between 2009 and 2014 a total of 724 patients with 713 singleton pregnancies, 10 twin and one triplet pregnancy were examined. Mean maternal age was 35,8 years, 261 patients were primigravidae.

Indications for invasive testing were suspicious first trimester screenings with either increased nuchal translucency, elevated risk for trisomy 13, 18 or 21 by biochemistry results from PAPP-A and free B-HCGor a combined elevated risk in 265 cases (36\%). 113 pregnancies hadsuspicious ultrasound findings in the first or second trimester (15\%). 91 patients were referred to our hospital for invasive testing due to a family history with chromosomal or genetic aberrations (12\%). Maternal age as the only indication for invasive testing was documented in 256 cases (34\%), the mean maternal age in this group was 39,2 years. 23 patients (3\%) had a combination of various indications, e.g. personal request or maternal infections such as cytomegaly (Figure 1).

Invasive testing was achievedby amniocentesis (AC) in 500 cases (69\%) and chorionic villi sampling (CVS) in 224 cases (31\%). (Table 1)

In total, we detected 123 pathologic karyotypes (17\%) and 601 normal karyotypes (83\%).

\begin{tabular}{|l|l|l|l|}
\hline $\begin{array}{l}\text { Indication of prenatal } \\
\text { invasive procedures for fetal } \\
\text { karyotyping }\end{array}$ & $\begin{array}{l}\text { AC } \\
(\mathrm{n}=500)\end{array}$ & $\begin{array}{l}\text { CVS } \\
(\mathrm{n}=224)\end{array}$ & $\begin{array}{l}\text { Total } \\
(\mathrm{n}=724)\end{array}$ \\
\hline $\begin{array}{l}\text { Suspicious first trimester } \\
\text { screening }\end{array}$ & 120 & 145 & 265 \\
\hline Increased nuchal translucency & 19 & 36 & 55 \\
\hline Suspicious biochemistry & 79 & 46 & 125 \\
\hline Combined elevated risk & 22 & 63 & 85 \\
\hline Maternal age & 223 & 33 & 256 \\
\hline Suspicious genetic history & 50 & 41 & 91 \\
\hline Suspicious ultrasound findings & 95 & 18 & 113 \\
\hline $\begin{array}{l}\text { Other indications (request, } \\
\text { infections, etc.) }\end{array}$ & 23 & 0 & 23 \\
\hline $\begin{array}{l}\text { * Total number of indications larger than total population due to } \\
\text { double indication }\end{array}$ \\
$\begin{array}{l}\text { Table 1: Indications of prenatal invasive procedures for fetal karyotyping } \\
\text { according to AC and CVS. }\end{array}$
\end{tabular}

Int J Gynecol Clin Pract

ISSN: 2394-4986

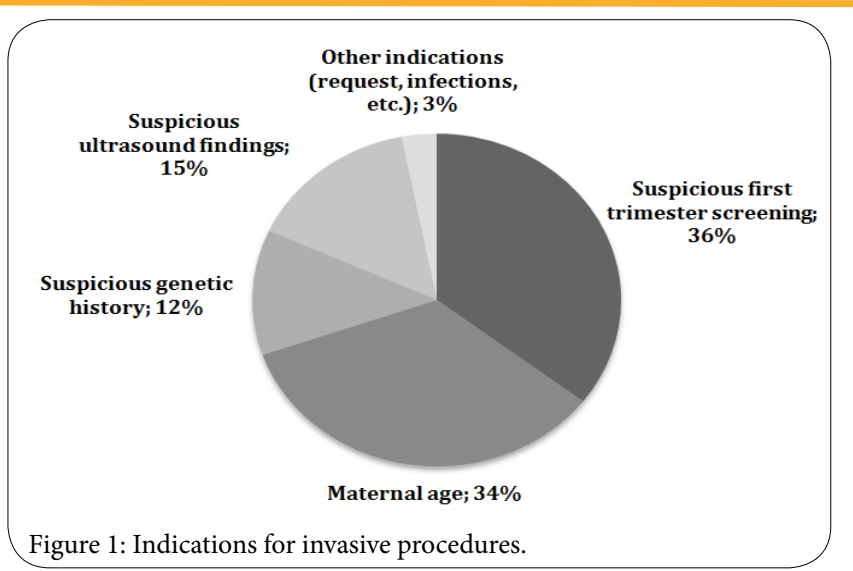

Pathologic karyotypes according to indication for invasive testing

Most frequently, as, expected, we diagnosed46 cases (37\%) of trisomy 21, 24 cases (19\%) of trisomy 18 and four cases (3\%) of trisomy $13.15 \%$ of the karyotypeswere triploidies (7), 45,X0 (4), 47,XYY (5), $47, \mathrm{XXX}(2)$ and 47,XY+4 (1). Furthermore we diagnosed eightcases (7\%) with translocations and tencases (8\%) with mosaic status. 11 cases (9\%) were diagnosed as microdeletions or duplications (Figure 2).

$63(52 \%)$ pathologic karyotypes were diagnosed by an AC, and 60 (48\%)pathologic karyotypes were diagnosed by a CVS. The main indication for CVS was a suspicious first trimester screening in 55 cases (44\%), whereas AC had a higher percentage of maternal age, suspicious ultrasound findings or genetic indications. Altogether 21 patients $(17 \%)$ with a suspicious first trimester screening did not opt for immediate CVS, but decided to have an AC in the second trimester. Eight of these patients had their first trimester screening in other institutions and were referred to our centre for invasive testing after $13+6$ weeks of gestation.

The 46 cases of trisomy 21 were diagnosed by CVS (27) in 59\% and AC (19) in $41 \%$ of the cases. All of them had a suspicious first trimester screening or additional abnormal ultrasound findings such as $\mathrm{AV}$ channel ( 3 cases), fetal hydrops ( 9 cases), short femur, distended jugular lateral sacs, polyhydramnios, duodenal atresia, hypoplastic nasal bone, tricuspid insufficiency orhydronephrosis.

The 24 cases of trisomy 18 were diagnosed by CVS (17) in $70 \%$ and $\mathrm{AC}$ (7) in $30 \%$.All of them had some typical ultrasound findings such as a fetalomphalocele or heart defects.

Trisomy 13 (4) and turner syndrome (4) were diagnosed by CVS in three cases and AC in one case, respectively. All of them had the typical ultrasound findings such as holoprosencephaly, heart defects and fetalhydrops.

We diagnosed seven cases of triploidyby AC (5) and CVS (2), showing severe fetal retardation and oligohydramnios.

With respect to risk calculations in the first trimester screening for trisomy 21, 18 and 13 we obtained the following results: from 60 patients 57 cases (95\%) had an adjusted risk of less than 1:50 and three cases $(5 \%)$ of more than 1:100. From these three cases two trisomy 21 fetuses had an NT of $2.6 \mathrm{~mm}$. One trisomy 18 fetus had an NT of $2.0 \mathrm{~mm}$ with unsuspicious biochemistry but revealed definite other ultrasound markers such as an omphalocele and a ventricular septal defect. 


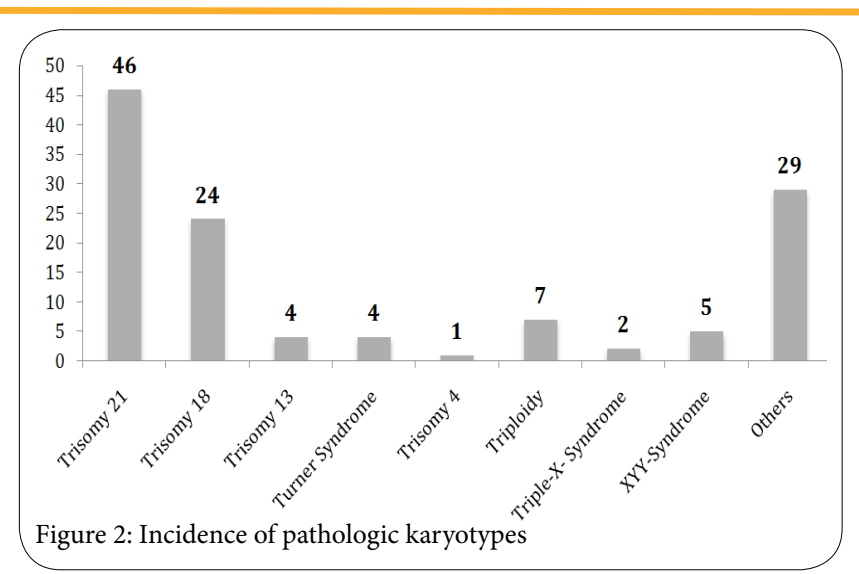

\section{Normal karyotypes according to indication for invasive testing}

189 patients (26\% of the overall population) with a normal fetal karyotype had an invasive procedure following a suspicious first trimester screening, 99 of those patients had an AC and 90patients had aCVS. 115 of these cases had suspicious biochemistry results, 36 patients had an NT above $2.5 \mathrm{~mm}$ and 38 patients had a combined risk elevation. Of these patients 60 women had an adjusted risk of less than 1:50.

79 patients opted for invasive testing due to pathologic ultrasound findings during first and second trimester screening, 20 patients had various other indications such as fear of fetal chromosomal aberrations in general. 242 of 256 patients (94\%) with maternal age as the only indication for invasive testing had normal fetal karyotypes. 77 patients had a family history with genetic diseases (Table 3).

\begin{tabular}{|l|l|l|l|}
\hline $\begin{array}{l}\text { Indication of prenatal invasive } \\
\text { procedures with normal fetal } \\
\text { karyotype }\end{array}$ & $\begin{array}{l}\text { AC } \\
(\mathrm{n}=437)\end{array}$ & $\begin{array}{l}\text { CVS } \\
(\mathrm{n}=164)\end{array}$ & $\begin{array}{l}\text { Total } \\
(\mathrm{n}=601)\end{array}$ \\
\hline $\begin{array}{l}\text { Suspicious first trimester } \\
\text { screening }\end{array}$ & 99 & 90 & 189 \\
\hline Increased nuchal translucency & 11 & 25 & 36 \\
\hline Suspicious biochemistry & 74 & 41 & 115 \\
\hline Combined elevated risk & 14 & 24 & 38 \\
\hline Maternal age & 209 & 33 & 242 \\
\hline Suspicious genetic history & 41 & 36 & 77 \\
\hline Suspicious ultrasound findings & 74 & 5 & 79 \\
\hline $\begin{array}{l}\text { Other indications (request, } \\
\text { infections, etc.) }\end{array}$ & 20 & 0 & 20 \\
\hline $\begin{array}{l}\text { * Total number of indications larger than total population due to } \\
\text { double indication }\end{array}$ & $\begin{array}{l}\text { Table 3: Indication of prenatal invasive procedures with a normal fetal } \\
\text { karyotype. }\end{array}$ \\
\hline
\end{tabular}

To all of our knowledge we had no report on a missed diagnosis of trisomy 21,18 or 13 after a first trimester screening.Overall reported fetal loss after invasive testing was less than $0.5 \%$, which was one CVS and no AC. There were two reported leakages after AC followed by normal term births.

\section{Discussion}

Prenatal diagnosis has experienced some tremendous shifts in counselling women with respect to the risks of fetal chromosomal aberrations. While in the last century maternal age was the main indication for invasive testing by AC or CVS in early pregnancies, nowadays women are recommended to have a first trimester screening including NT measurement and detailed ultrasound evaluation of the fetus. Furthermore, early fetal echocardiography and neurosonography may improve the diagnostic results $[8,9]$. Moreover, it is the intention to counsel patients with respect to possible pregnancy complications such as preeclampsia, intrauterine growth restriction (IUGR) or maternal diabetes mellitus [10].

Certainly, another major problem in prenatal counselling nowadays is the rising number of pregnancies after ART treatment. Naturally, many women in this population have an advanced age so that their personal risk for a pregnancy with chromosomal aberrations is elevated. Also naturally, the fear for fetal loss with or without invasive procedures is immense. Therefore, these patients are in the need of an extremely careful prenatal counselling recommending an ultrasound examination including a correct risk calculation for chromosomal aberrations or further pregnancy complications.

In our study, first trimester screening had a good prognostic reliability for invasive testing. From 60 cases with trisomy 21, 18 and 13 , as much as $95 \%$ had an adjusted risk of more than 1:50. This is in good congruence with or even better than the standards suggested by the FMF London [11].

Furthermore, adding surplus markers from fetal echocardiography such as pathologic Doppler in the ductusvenosus or tricuspid regurgitation helped to identify severe cases of Turner's syndrome in our cohort. In 2009 Kagan and co-workers as well as Maiz and coworkers published their data proving the importance of extended ultrasound examinations of the fetal heart $[12,13]$.

From 123 pathologic karyotypes we identified 38 chromosomal aberrations (31\%), which are not supposed to be detected by first trimester screening such as sex chromosomal aberrations, translocations or micro deletions. The main indication for invasive testing in these cases was a suspicious ultrasound screening in either the first or second trimester. Translocations and chromosomal mosaicism in association with severe abnormal ultrasound findings have a major impact on counselling parents prenatally with respect to the fetal outcome.

On the other hand, certain sex chromosomal aberrations such as triple X syndrome or Klinefelter syndrome, in our opinion, require very distinct counselling with respect to induced abortions [14].

$35 \%$ of our patients had an invasive prenatal testing due to their maternal age alone. These numbers have constantly declined over the six-year period of this study. Furthermore, like in previous other studies, we found constantly declining numbers of AC in relation to CVS. This is in accordance with a study by Tabor and co-workers. They found a constantly decreasing number of AC over a period of eleven years, whereas CVS procedures according to suspicious first trimester screening results were rising [15]. The results of our study support the fact that major indications for an $\mathrm{AC}$ may be pathologic ultrasound findings in the second trimester screening or several genetic family risks that can be detected in amniocytes rather than chorionoc villi due to a better resolution of the karyogram [16].

Nonetheless women attitude toward prenatal diagnosis depends on various implications. Although the numbers of invasive prenatal testing are constantly declining, there are patients who opt for a primary fetal karyotyping. Definitely, the major argument of these 
Citation: Eckmann-Scholz C, Berninghaus C, Farrokh A, Maass N, Alkatotut I (2016) Prenatal Invasive Fetal Karyotyping in the Era of First Trimester Screening and Noninvasive Prenatal Testing (NIPT). Int J Gynecol Clin Pract 3: 116. doi: http://dx.doi.org/10.15344/2394-4986/2016/116

Page 4 of 4

patients is the fear of a life with a severely impaired child. Counselling these parents must, at least, include all aspects and options of legal termination of pregnancy [17].

Results from non-invasivecff DNA testing (NIPT) are promising, as far as trisomy 21,18 and 13 or sex chromosomal aberrations are concerned. Results with respect to the detection of microdeletions are promising, as well $[14,18]$.

Nevertheless, there is a worldwide consensus that, for the moment being, pathologic results from cffDNA must be confirmed by invasive testing.

Once again our results show that the defined pathologic ultrasound findings such as heart defects, abdominal wall defects, absent nasal bone or growth restriction in the first or second trimester, have a good correlation with aberrant fetal karyotypes and should be followed by an invasive testing, if this is an option for the parents. In contrast, suspicious biochemistry analysis without abnormal ultrasound findings may be an indication for a cffDNA prenatal testing.

\section{Conclusion}

We could show once again that combined first trimester screening is a reliable method for aneuploidy screening in the hands of experts. Maternal age alone should, no further, be an indication for invasive prenatal testing. A distinct family history remains one indication for molecular genetic testing as well as suspicious ultrasound findings at any time of pregnancy [19].

Furthermore, our own number of fetal losses with less than $0.5 \%$ suggests that invasive prenatal procedures are a rather safe method in the hand of an experienced operator.

\section{Competing Interests}

The authors declare that they have no competing interests.

\section{References}

1. Snijders RJ, Noble P, Sebire N, Souka A, Nicolaides KH (1998) UK multicentre project on assessment of risk of trisomy 21 by maternal age and fetal nuchal-translucency thickness at 10-14 weeks of gestation. Fetal Medicine Foundation First Trimester Screening Group. Lancet 352: 343346

2. Souka AP, Snijders RJ, Novakov A, Soares W, Nicolaides KH (1998) Defects and syndromes in chromosomally normal fetuses with increased nuchal translucency thickness at 10-14 weeks of gestation. Ultrasound Obstet Gynecol 11: 391-400.

3. Bilardo CM, Müller MA, Pajkrt E, Clur SA, van Zalen MM, et al. (2007) Increased nuchal translucency thickness and normal karyotype: time for parental reassurance. Ultrasound Obstet Gynecol 30: 11-18.

4. Nicolaides $\mathrm{KH}$ (2004) Nuchal translucency and other first-trimester sonographic markers of chromosomal abnormalities. Am J Obstet Gynecol 191: 45-67.

5. Wilson RD, Langlois S, Johnson JA; Society of Obstetricians and Gynaecologists of Canada (2007) Mid-trimester amniocentesis fetal loss rate. J Obstet Gynaecol Can 29: 586-595.

6. Akolekar R, Beta J, Picciarelli G, Ogilvie C, D'Antonio F (2015) Procedurerelated risk of miscarriage following amniocentesis and chorionic villus sampling: a systematic review and meta-analysis. Ultrasound Obstet Gynecol 45:16-26

7. Pandya PP, Snijders RJ, Johnson SP, De Lourdes Brizot M, Nicolaides KH (1995) Screening for fetal trisomies by maternal age and fetal nucha translucency thickness at 10 to 14 weeks of gestation. Br J Obstet Gynaecol 102: 957-962.

Int J Gynecol Clin Pract

ISSN: 2394-4986
8. Chaoui R, Nicolaides KH (2010) From nuchal translucency to intracranial translucency: towards the early detection of spina bifida. Ultrasound Obstet Gynecol 35:133-138.

9. Wiechec M, Knafel A, Nocun A (2015) Prenatal detection of congenital heart defects at the 11- to 13-week scan using a simple color Doppler protoco including the 4-chamber and 3-vessel and trachea views. J Ultrasound Med 34: 585-594.

10. Nicolaides $\mathrm{KH}$ (2011) A model for a new pyramid of prenatal care based on the 11 to 13 weeks' assessment. Prenat Diagn 31: 3-6.

11. Kagan KO, Etchegaray A, Zhou Y, Wright D, Nicolaides KH (2009) Prospective validation of first-trimester combined screening for trisomy 21 . Ultrasound Obstet Gynecol 34: 14-18.

12. Maiz N, Valencia C, Kagan KO, Wright D, Nicolaides KH (2009) Ductus venosus Doppler in screening for trisomies 21, 18 and 13 and Turner syndrome at 11-13 weeks of gestation. Ultrasound Obstet Gynecol 33: 512-517.

13. Kagan KO, Etchegaray A, Zhou Y, Wright D, Nicolaides KH (2009) Prospective validation of first-trimester combined screening for trisomy 21. Ultrasound Obstet Gynecol 34: 14-18

14. Srinivasan A, Bianchi DW, Huang H, Sehnert AJ, Rava RP (2013) Noninvasive detection of fetal subchromosome abnormalities via deep sequencing of maternal plasma. Am J Hum Genet 92: 167-176.

15. Tabor A, Vestergaard CH, Lidegaard O (2009) Fetal loss rate after chorionic villus sampling and amniocentesis: an 11-year national registry study. Ultrasound Obstet Gynecol 34: 19-24.

16. Chitayat D, Langlois S, Wilson RD (2011) Genetics Committee of the Society of $O$, Gynaecologists of C, Prenatal Diagnosis Committee of the Canadian College of Medical G: Prenatal screening for fetal aneuploidy in singleton pregnancies. J d'obstetrique et gynecol 33: 736-750.

17. Grinshpun-Cohen J, Miron-Shatz T, Rhee-Morris L, Briscoe B, Pras E, et al. (2015) A Priori Attitudes Predict Amniocentesis Uptake in Women of Advanced Maternal Age: A Pilot Study. J Health Commun 20: 1107-1113.

18. Gil MM, Akolekar R, Quezada MS, Bregant B, Nicolaides KH (2014) Analysis of cell-free DNA in maternal blood in screening for aneuploidies: meta-analysis. Fetal Diagn Ther 35: 156-173.

19. Devers PL, Cronister A, Ormond KE, Facio F, Brasington CK, et al. (2013) Noninvasive prenatal testing/noninvasive prenatal diagnosis: the position of the National Society of Genetic Counselors. J Genet Couns 22: 291-295. 